 \\ Revista aSEPHallus de Orientação Lacaniana Núcleo Sephora de Pesquisa sobre o Moderno e o Contemporâneo ISSN $1809-709 \mathrm{X}$
}

\section{Defesa e sexualidade nos primórdios da psicanálise}

André Oliveira Costa

Psicanalista

Doutor em Educação pela Universidade Federal do Rio Grande do Sul / UFRGS (Rio Grande do Sul, Brasil) Mestre em Filosofia pela Pontifícia Universidade Católica do Rio Grande do Sul / PUC-RS (Rio Grande do Sul, Brasil)

Membro da Associação Psicanalítica de Porto Alegre / APPOA (Rio Grande do Sul, Brasil)

E-mail: androlicos@gmail.com

\begin{abstract}
Resumo
Este artigo pretende investigar como a teoria da defesa que Sigmund Freud propõe no início de suas pesquisas possibilitou a consideração da sexualidade como causa das psiconeuroses. Nesse sentido, afasta-se das leituras que consideram a psicanálise como uma teoria culturalista, isto é, uma teoria que determina os processos psíquicos prevalentemente a partir de fatores sociais e culturais. Percorrendo os artigos pré-psicanalíticos, o autor mostra como Freud se separa dos seus mestres e também como expande a noção de sexualidade para as excitações de outras zonas corporais, ideia que vem a ser desenvolvida na caracterização da sexualidade das crianças como perverso-polimorfa. Palavras-chave: psicanálise, teoria da defesa, sexualidade, etiologia.
\end{abstract}

\section{Défense et sexualité dans les origines de la psychanalyse}

Cet article propose d'investiguer la façon don't la théorie de la défense que Sigmund Freud a proposé au début de ses recherches a rendu possible la considération de la sexualité comme la cause des psychonévroses. Dans ce sens il s'écarte des lectures qui considèrent la psychanalyse comme une théorie culturaliste, c'est a dire, une théorie qui détermine les processus psychiques surtout d'élements sociaux et culturels. Tout en faisant un parcours des écrits pré-psychanalytiques, l'auteur nous montre comment Freud se sépare de ses professeurs et aussi comment il élargit la notion de sexualité pour comprendre l'excitation d'autres zones du corps, une idée qui sera développée dans la définition de la sexualité des enfants comme perverse-polimorphe.

Mots-clés: psychanalyse, théorie dela défense, sexualité, éthiologie.

\section{Defense and sexuality in the dawn of psychoanalysis}

This article aims to investigate the manner in which the defense theory that Sigmund Freud proposed in his early research, made it possible to consider sexuality as the cause of psychoneuroses. In this sense he strays from the readings that consider psychoanalysis as culturalist theory, which means it is a theory that defines the psychological processes as mainly social and cultural products. While he courses through pre-psychoanalytic writings. The author shows us how Freud separates himself from his masters and also how he expands on the concept of sexuality in order to understand the excitement of other parts of the body, an idea that will be develloped into the definiton of children's sexuality as polymorphous perverse.

Key-words: psychoanalysis, defense theory, sexuality, etiology. 


\section{Defesa e sexualidade nos primórdios da psicanálise}

\section{André Oliveira Costa}

Através do estudo com o neurologista francês Jean-Martin Charcot, Freud modificou o objeto de suas pesquisas, passando dos fenômenos neurológicos para a clínica das neuroses, e mais especificamente para a clínica da histeria. Em 1888, dois anos depois de voltar de Paris, Freud contribuiu com a Enciclopédia Villaret, escrevendo o verbete sobre a histeria. Nesse texto, intitulado Histeria, vemos, de forma bastante clara, a influência de Charcot na compreensão sobre a causa dos sintomas histéricos. Assim como o neurologista francês, Freud afirmava, na época, que "a etiologia do status hystericus deve ser buscada inteiramente na hereditariedade: os histéricos sempre têm uma disposição hereditária para perturbações da atividade nervosa" (Freud, 1888, p. 96). Isto é, seu ponto de vista ainda era o da predominância da hereditariedade como fator etiológico, enquanto que "todos os outros fatores situam-se em lugar secundário e assumem o papel de causas incidentais, cuja importância é quase sempre superestimada na prática" (Freud, 1888, p. 96). A participação da sexualidade sobre a patologia histérica era, para Freud, compreendida como sendo "causas acidentais da histeria", pois estas "desencadeiam o início de ataques histéricos, de histerias agudas" (Freud, 1888, p. 96).

Apesar disso, em 1888, Freud admite existir uma participação da vida sexual na etiologia da histeria, "assim como em todas as outras neuroses", apenas em decorrência da significação funcional que a sexualidade possui para a vida psíquica do sujeito. Mas, para ele, a importância da sexualidade era superestimada por aquelas pessoas que a consideravam o fator principal da etiologia das neuroses, pois, comparando a sexualidade com os efeitos hereditários, ela era considerada apenas causa incidental. Os fatores hereditários eram, portanto, a principal hipótese das causas tanto dos sintomas físicos, quanto dos distúrbios psíquicos das neuroses.

O princípio causador da histeria, apresentado nesse texto de 1888, foi resumido por Freud como sendo "alterações na distribuição normal, no sistema nervoso, das quantidades estáveis de excitação" (Freud, 1888, p. 95). Este princípio é explicado, de maneira mais detalhada, pelo fato de que os sintomas da histeria são o resultado do trabalho que o doente tem que fazer com "um excesso de excitação no sistema nervoso - excesso que se manifesta ora como inibidor, ora como irritante, deslocando-se com grande mobilidade dentro do sistema nervoso" (Freud, 1888, p. 96).

Essa excitação excedente que resulta do evento traumático não leva, no momento exato do acontecimento, à produção dos sintomas histéricos. Isso se deve, segundo Freud, porque "a evolução dos distúrbios histéricos muitas vezes exige uma espécie de incubação, ou melhor, um período de latência, durante o qual a causa desencadeante continua atuando no inconsciente" (Freud, 1888, p. 100). A referência à temporalidade indica a formação da neurose não através de um, mas de dois tempos, intercalados por um período de latência. Freud já faz notar aqui um traço fundamental da psicanálise, a saber, que o registro psíquico dos acontecimentos segue a temporalidade de tradução $a$ posteriori, de ressignificação de um acontecimento primeiro. 
Ganha destaque também a importância da quantidade de uma energia para a formação de sintomas histéricos, mas ainda sem nenhuma marca de sexualidade. Freud, em "Estudos sobre histeria", confirma sua desconsideração sobre o fator da sexualidade, quando faz referência ao tratamento realizado com a Sra. Emmy von N., que ocorreu por volta de 1889. No relato desse caso, Freud escreve:

Quando comecei a analisar a segunda paciente, a Sra. Emmy von N., a expectativa de que a base da histeria fosse uma neurose sexual estava muito longe de minha mente. Eu acabara de sair da escola de Charcot e encarava a ligação da histeria com o tema da sexualidade como uma espécie de insulto - exatamente como fazem as próprias pacientes. (Freud \& Breuer, 1893-1895, p. 257)

Na sequência dessa citação, Freud faz uma retrospectiva dos cinco casos apresentados por ele neste livro e conclui: "naquela época, eu ainda não submetia tais casos a uma investigação deliberada e minuciosa de sua base sexual neurótica". Entretanto, o tema da sexualidade não era um assunto que estava tão distante do pensamento de Freud. Presente em momentos esquecidos pelo tempo, Freud (1914) relembra, anos mais tarde, no texto "A história do movimento psicanalítico", três acontecimentos que envolveram a inclusão da sexualidade na etiologia das neuroses e que tiveram importância por ocorrerem anteriormente aos primeiros atendimentos clínicos realizados pela clínica psicanalítica. Essas situações que se passaram com Freud envolvem três importantes figuras para a formação de seu pensamento: Josef Breuer, Charcot e Rudolph Chrobak, professor de ginecologia da Universidade de Viena. Para Freud, esses professores teriam transmitido a ele "um conhecimento que, rigorosamente falando, eles próprios não possuíam" (Freud, 1914, p. 23). Talvez, o "desconhecimento" dos próprios autores dessa ideia sobre a sexualidade como etiologia das neuroses tenha sido o motivo pelo qual Freud não percebeu a significação que ela tinha no momento em que foi dita, permanecendo, então, de forma latente em seu pensamento.

O primeiro acontecimento relatado por Freud ocorreu com Breuer, quando este, após ter sido interceptado pelo marido de uma paciente que trazia notícias sobre a doença de sua esposa, teria comentado com Freud que essas doenças "são sempre secrets d'alcôve" (Freud, 1914, p. 24). A segunda situação que Freud relatou se deu com Charcot, quando o escutou comentando com um colega sobre o caso de um casal em que a mulher sofria de uma neurose grave e o homem de impotência sexual. Charcot, respondendo à surpresa de seu colega, teria dito a ele: "Mais dans des cas pareils c'est toujurs la chose génitale, toujours...toujours...toujours". O terceiro acontecimento relembrado por Freud como fazendo parte dos primórdios da relação da sexualidade como causa das neuroses foi um comentário feito pelo professor Chrobak sobre uma paciente que sofria de acessos de ansiedade sem sentido. Essa mulher, casada há 18 anos com um homem impotente, 
ainda era virgem, e a recomendação feita pelo professor para a cura das crises dela foi " $R p$. Penis normalis dosim repetatur!".

Sabemos que a teoria psicanalítica elaborada por Freud só pôde se desenvolver a partir do afastamento de dois desses personagens citados anteriormente. $\mathrm{O}$ primeiro a ter seu pensamento reformulado foi Charcot. Foi pela importância de seu trabalho com a histeria, constatando que os sintomas poderiam ser produzidos ou removidos pela hipnose, que o neurologista francês influenciou as ideias de Freud. Mas Charcot não dispunha de nenhuma teoria que explicasse o funcionamento dessa patologia, respondendo apenas sobre sua causa, a saber, a ocorrência de um evento traumático (agents provocateurs) e uma predisposição psíquica hereditária. Freud percebia essa limitação do pensamento de Charcot, e encontrou, em Breuer, uma teoria psicológica que dava conta dessa falha, explicando o funcionamento da histeria pelas ideias dos estados hipnoides e utilizando para tratamento o método catártico.

No decorrer do trabalho com Breuer, entretanto, Freud ainda não estava satisfeito com as explicações sobre a patologia da neurose. Acreditava haver outras concepções que não estavam sendo abarcadas pelas investigações da época. $\mathrm{O}$ afastamento de Breuer foi fundamental para Freud reestruturar as concepções sobre as causas da histeria, considerando então a sexualidade e a defesa como fatores fundamentais para a construção de seu edifício teórico. Essa ruptura ocorreu durante a produção conjunta dos "Estudos sobre histeria", e também foi motivada pelas modificações que Freud fazia na técnica terapêutica que Breuer Ihe havia apresentado.

Segundo Freud - no capítulo que escreveu sobre "A psicoterapia da histeria" -, quando começou a trabalhar com o método catártico em um número maior de pacientes, deparou-se com dificuldades que o obrigaram a modificar a técnica de tratamento, na medida em que não estava mais conseguindo hipnotizar todos os pacientes. Freud não negava o valor funcional do método catártico, quando afirma que ele "não deve ser considerado sem valor pelo fato de ser sintomático, e não causal, pois a rigor a terapia causal é, via de regra, uma terapia profilática" (Freud \& Breuer, 1893-1895, p. 259). A impossibilidade de resolver por completo os sintomas histéricos pela ação terapêutica (na medida em que esta age apenas sobre o sintoma e não em sua causa) ocorria quando se tratavam de sintomas que persistiam com a utilização da hipnose, pois não tinham suas causas extinguidas. Sobre esses casos, Freud escreve que:

(...) quando se trata de histerias que seguem um curso crônico, acompanhadas de uma produção moderada, mas constante, de sintomas histéricos, encontramos a mais forte razão para lamentar nossa falta de uma terapia que tenha eficácia causal, mas temos também os maiores motivos para apreciar o valor do processo catártico como terapia sintomática. (Freud \& Breuer, 1893-1895, p. 260)

Em função da dificuldade em hipnotizar alguns pacientes, o método catártico foi sendo substituído pela concentração. Esta técnica era aplicada nos pacientes acordados, auxiliando suas 
falas com uma leve pressão em suas testas. Mesmo assim, Freud deparou-se com o mesmo tipo de problema. Através da concentração, as lembranças que surgiam ainda exigiam um esforço de superação de resistências:

(...) por meio de meu trabalho psíquico eu tinha que superar uma força psíquica nos pacientes que se opunha a que as representações patogênicas se tornassem conscientes (fossem lembradas). Uma nova compreensão pareceu abrir-se ante meus olhos quando me ocorreu que esta sem dúvida deveria ser a mesma força psíquica que desempenhara um papel na geração do sintoma histérico e que, na época, impedira que a representação patogênica se tornasse consciente. (Freud \& Breuer, 1893-1895, p. 264)

E diante dessa constatação, Freud se pergunta: "Que espécie de força poder-se-ia supor que estivesse em ação ali, e que motivo poderia tê-la posto em ação?". Aqui vemos o problema enfrentado por Freud: ele se deparava com elementos diferentes daqueles que apareciam com a utilização da técnica da hipnose. A dificuldade de chegar à causa dos sintomas já não cabia mais à técnica utilizada, na medida em que a própria natureza do mecanismo psíquico impunha certas forças contra as representações psíquicas.

Freud, nesse momento, mostra a necessidade de reformular a ideia a fim de dar conta dessa força de caráter oposta ao trabalho do psicanalista. Elabora, então, um dos conceitos fundamentais da psicanálise, a saber, a resistência psíquica sobre o material inconsciente. Segundo a teoria da defesa, com o surgimento de uma representação incompatível, o eu provoca uma força de repulsão para se defender dela, afastando-a da consciência e da memória. Ora, através da técnica da concentração, e não mais pela hipnose, Freud conseguia que eles se lembrassem da representação patógena. Mas esta nem sempre era reconhecida por eles como tal: "Uma lembrança patogênica é reconhecível, entre outras coisas, pelo fato de o paciente a descrever como sem importância e, não obstante, só enunciá-las sob resistência. Também existem casos em que o paciente tenta renegá-la mesmo após seu retorno" (Freud \& Breuer, 1893-1895, p. 273).

Após solucionar a primeira dificuldade que havia encontrado com a utilização do método catártico de Breuer - que explicava o porquê de sua dificuldade em hipnotizar apenas alguns pacientes -, Freud busca responder à segunda dificuldade, que diz respeito às concepções teóricas nas quais ele se baseava para compreender o fenômeno da histeria. Para Freud, os pressupostos que foram apresentados no capítulo "Comunicação Preliminar", dos "Estudos sobre histeria", não poderiam mais dar conta da concepção sobre esta neurose, muito menos de outras psicopatologias. Sua pergunta, então, passa a investigar a validade da formação de todas as neuroses a partir do pressuposto da teoria das resistências. Assim, em "As neuropsicoses de defesa" (1894a), Freud descreve as semelhanças e diferenças que existem entre o funcionamento histérico e as outras psicopatologias: a obsessão, a fobia e a paranoia. Neste artigo, as neuroses são tratadas sob um 
denominador comum, ou seja, a atuação do mecanismo de defesa sobre uma representação incompatível. De modo resumido, podemos dizer que essa defesa é a responsável pela escolha da neurose e seu funcionamento pode ser dividido em dois tempos. No primeiro, existe uma dissociação da ideia de sua carga afetiva, enfraquecendo-a e a excluindo da consciência. O segundo momento, que é propriamente o momento da "escolha", diz respeito ao que é feito com essa carga afetiva. Aparece, então, uma importante diferenciação entre as neuroses. Na neurose obsessiva e na fobia, observamos a ação da defesa sobre o afeto, de modo a deslocá-lo para uma outra representação; mecanismo chamado por Freud de deslocamento ou substituição. Enquanto que, na histeria, a conversão do afeto em sintomas somáticos é a causa desta neurose.

Este artigo de 1894 já nos apresenta um tópico de fundamental importância para a construção do edifício teórico da psicanálise, que faz parte das causas comuns das psiconeuroses. Trata-se da natureza da representação incompatível com o eu que, em função de seu conteúdo, suscitou afetos aflitivos. Sobre a histeria, Freud ainda parece duvidoso quanto a sua hipótese: "esse tipo de representações incompatíveis assoma principalmente no campo da experiência e das sensações sexuais" (Freud, 1894a, p. 55). Quando descreve o processo de formação da neurose obsessiva e da fobia, a certeza sobre a natureza sexual da representação ainda não the parece também tão segura. Na segunda parte desse trabalho, encontramos a seguinte afirmação:

Em todos os casos que analisei, era a vida sexual do sujeito que havia despertado um afeto aflitivo precisamente da mesma natureza do ligado à sua obsessão. Teoricamente, não é impossível que esse afeto possa às vezes emergir em outras áreas; resta-me apenas relatar que, até o momento, não deparei com nenhuma outra origem. Ademais, é fácil verificar que é precisamente a vida sexual que traz em si as mais numerosas oportunidades para o surgimento de representações incompatíveis. (Freud, 1894a, p. 59)

Se voltarmos dois anos antes à publicação desse texto, isto é, na "Comunicação Preliminar" (1893) - (primeiro capítulo do "Estudos sobre histeria", escrito com Breuer, provavelmente em dezembro de 1892) -, a sexualidade ainda não era vista como fator fundamental para o desenvolvimento da neurose histérica. Foi com a descoberta da teoria da defesa que Freud pôde reconhecer o papel da sexualidade e da excitação sexual na etiologia das neuroses, substituindo assim a hereditariedade como a causa principal destas patologias. As descobertas da resistência e da teoria da defesa fizeram com que Freud começasse a se afastar das ideias sobre a hereditariedade.

E Freud aposta cada vez mais na marca da sexualidade como elemento fundamental para a produção das psiconeuroses. Por volta de 1894 e 1896, ele publica uma série de artigos - dentre os quais três foram escritos em francês - buscando diferenciar as psiconeuroses das neurastenias a fim de, a partir dessa distinção, poder estabelecer uma etiologia própria do funcionamento psíquico em 
relação aos processos somáticos. Estes artigos espelham o afastamento de Freud e Breuer, que vinha ocorrendo durante a elaboração dos "Estudos sobre histeria", e ajudam a fortalecer a hipótese de Freud sobre a sexualidade e sua teoria da defesa como fundamentos das neuroses. Os atos de defesa do eu contra as representações incompatíveis as expulsam da consciência e "não deixam nenhum traço na memória do paciente" (Freud, 1894b, p. 84).

Em "Obsessões e fobias: seu mecanismo psíquico e sua etiologia", publicado em 1894, Freud aprofunda as hipóteses que apresentou no artigo "As neuropsicoses de defesa" sob a perspectiva detalhada dessas duas grandes neuroses. Assim, nas obsessões e fobias, que também podem, como a histeria, ser chamadas de traumáticas, correspondem "(1) uma representação que se impõe ao paciente; (2) um estado emocional associado" (Freud, 1894b, p. 79). Enquanto na fobia esse estado emocional é o de angústia, na neurose obsessiva é o de dúvida, de remorso ou de raiva.

Sendo caracterizada como traumática, a obsessão segue o mesmo movimento de produção da histeria, a saber, a representação associada à sintomatologia não é mais a representação original, mas uma representação substitutiva. A hipótese de Freud é a de que todas as representações substituídas possuem um atributo comum: elas "correspondem a experiências realmente penosas na vida sexual do sujeito, que ele se esforça para esquecer" (Freud, 1894b, p. 79). A neurose obsessiva, então, se caracteriza por substituir a representação original - incompatível com a consciência por seu caráter sexual - por outra representação ou por comportamentos que servem como medida de alivio e proteção. A nova representação passa a ser associada ao estado emocional original, produzindo uma mésalliance, uma falsa ligação que faz com que os sintomas obsessivos se organizem por vezes de maneiras incompreensíveis.

Já a fobia, por sua vez, não opera por substituição de representações. Seu mecanismo de defesa é totalmente diferente do mecanismo das obsessões. O que caracteriza as fobias é seu estado emocional, a angústia. $\mathrm{E}$, afirma Freud, "tanto quanto posso perceber, também a neurose de angústia tem uma origem sexual, mas não se prende a representações extraídas da vida sexual" (Freud, 1894b, p. 85). Assim, através do estudo sobre o afeto de angústia, Freud começa a formular a hipótese de que todo o funcionamento psíquico está regulado por uma quantidade de afeto de origem sexual. Isso se dá na medida em que, ainda neste tempo, as representações incompatíveis com o eu eram consideradas de origem externa a ele. A dedução dessas representações sustentava sempre que acontecimentos reais produziram algum trauma psíquico nos pacientes.

Por meio do estudo sobre a angústia, fica claro como Freud pôde conceber uma sexualidade natural, própria ao corpo e independente de qualquer evento traumático. Segundo esta elaboração, que vai culminar em sua primeira teoria da angústia, a causa específica desta neurose não se deve a nenhum acontecimento real, mas a uma acumulação de tensão sexual produzida pela abstinência ou pela excitação sexual não consumada. Em 1895, um ano mais tarde à publicação do artigo "As neuropsicoses de defesa", Freud avança nos estudos sobre as neuroses de angústia. E com eles adentramos mais um pouco à formulação do conceito de pulsão sexual. 
No artigo "Sobre os fundamentos para destacar da neurastenia uma síndrome específica denominada 'neurose de angústia"', Freud parte da hipótese de que "um conjunto de perturbações e influências da vida sexual são os fatores etiológicos atuantes" (Freud, 1895, p. 93). Ele sustenta sua posição em relação à angústia como sendo o acúmulo de excitação sexual somática que não foi descarregada pelo sistema psíquico. Trata-se de uma hipótese que vinha sendo elaborada pouco a pouco. No "Rascunho E: Como se origina a angústia", enviado a Fliess em data desconhecida, mas cuja escrita é estipulada em 6 de junho de 1894, Freud mostra que, para ele, estava cada vez mais clara a associação da angústia com a sexualidade.

O que se destaca dessa primeira concepção sobre a angústia é a distinção que Freud estabelece entre a sexualidade no nível somático e os efeitos psíquicos que ela produz. No "Rascunho E", por exemplo, ele afirma: "a fonte da angústia não deve ser buscada na esfera psíquica. Por conseguinte, deve residir na esfera física: é um fato físico da vida sexual que produz a angústia" (Freud, 1894c, p. 78). Há um acúmulo de tensão sexual física que é consequência do impedimento da descarga, fazendo com que a angústia se produza como um efeito de represamento da sexualidade. Também na histeria encontramos esse mesmo processo, mas nela a excitação sexual é transformada em sintoma somático, enquanto que na neurose de angústia ela é transformada em afeto. Diante dessa distinção entre físico e psíquico, a melancolia é situada como o pólo oposto à neurose de angústia, na medida em que nela o acúmulo da tensão sexual psíquica faz com que o melancólico não tenha nenhum desejo sexual, mas uma ânsia de amor. Há na melancolia, então, um luto pela perda da libido.

Neste texto sobre a neurose de angústia, Freud afirma que "não se poderia atribuir a nenhuma origem psíquica a angústia que subjaz aos sintomas clínicos da neurose" (Freud, 1895, p. 108). Para ele, esse afeto é originado por um "acúmulo de excitação" de origem somática e de natureza sexual. Mas há uma outra parte, os efeitos psíquicos da sexualidade, que sofre decréscimo da "libido sexual, ou do desejo psíquico". A clássica definição do conceito de pulsão, apresentada no texto "Pulsões e destinos da pulsão" (1915), como um conceito limite entre o psíquico e o somático, como o representante psíquico dos estímulos que provêm do interior do corpo e afetam a psique, Freud neste momento, parece apresentar os dois lados da equação sem, no entanto, encontrar o articulador comum para ambos.

A partir da concepção sobre a formação da angústia, Freud descreve o mecanismo da sexualidade, tanto para os homens, quanto para as mulheres, do seguinte modo: uma excitação sexual somática (como uma forma de pressão do corpo) é produzida de forma contínua e, periodicamente, se torna um estímulo para a psique. Mas, para que essa excitação sexual somática se expresse como um estímulo psíquico, ela deve atingir um certo patamar. Destaca-se aqui duas marcas que vão caracterizar a pulsão: a pressão constante e a fonte, cuja origem é sempre somática. Seguimos com Freud: 
Depois que isso acontece, entretanto, o grupo de representações sexuais presente na psique fica suprido de energia e passa a existir um estado psíquico de tensão libidinal que traz em si uma ânsia de eliminar essa tensão. Uma descarga psíquica desse gênero só é possível por meio do que chamarei de ação específica ou adequada. (Freud, 1895, p. 109)

Essa ação específica consiste no ato reflexo do corpo e no preparo psíquico que possibilitam a descarga da energia sexual somática acumulada. Mas se essa energia não for adequadamente descarregada - o que pra Freud, neste momento, significa o ato sexual que não passa pela via psíquica -, a excitação sexual somática atinge um valor limite que se converte em excitação psíquica, em libido.

Tanto no "Rascunho E" (Freud, 1894c) como nesse artigo sobre a neurose de angústia, Freud faz uma importante diferenciação relativa às origens das afetações as quais o sistema psíquico está suscetível. De um lado, afirma Freud, "a psique é invadida pelo afeto de angústia quando se sente incapaz de lidar, por meio de uma reação apropriada, com uma tarefa (um perigo) vinda de ford" (Freud, 1895, p. 112). Há uma angústia que é produzida em função de uma excitação exógena, cuja fonte encontra-se do lado de fora do indivíduo e atinge a psique com uma quantidade de excitação. Para se proteger dessa condição, basta qualquer reação motora que diminua a excitação psíquica interna que foi produzida. Por outro lado - e aqui se apresenta um problema a ser resolvido pela psicanálise - há uma excitação sexual endógena, cuja "fonte reside no próprio corpo (fome, sede, impulso sexual)" (Freud, 1894c, p. 80).

Uma das características da força externa é agir em um único impacto, enquanto que a excitação interna é produzida como uma força constante, que cresce continuamente e somente é percebida ao atingir um certo limiar. Neste momento, então, ela se faz presente psiquicamente e se coloca em relação com algumas ideias ou grupos de ideias. A excitação sexual física, atingindo esse limiar, desperta a libido psíquica e, assim, apenas uma reação específica pode diminuir a quantidade de excitação produzida. A angústia surge quando essa excitação sexual somática não encontra nenhuma ligação psíquica suficiente que produza o desejo sexual. Seu acúmulo, então, transformase em angústia - e assim fica explicado também porque nas neuroses de angústia há uma diminuição da libido psíquica.

$\mathrm{Na}$ última parte do artigo "Sobre os fundamentos para destacar da neurastenia uma síndrome especifica denominada 'neurose de angústia'", Freud (1895) busca uma correlação da neurose de angústia com as outras grandes estruturas clínicas. Por um lado, a neurose de angústia parece ser o equivalente somático da histeria, na medida em que esta tem sua fonte em componentes psíquicos. Ambas decorrem do acúmulo de excitação e mostram uma insuficiência psíquica, ou seja, uma diminuição da libido sexual, pois, ao invés de elaborarem psiquicamente essa excitação sexual, acabam desviando-a para o próprio corpo. A diferença entre as duas, porém, segue a separação que Freud fixa entre o somático e o psíquico. Na neurose de angústia, trata-se de 
excitação sexual somática, enquanto que na histeria a excitação sexual é psíquica, fruto de um conflito de ideias.

Com isso, Freud parece se encaminhar para uma concepção geral de neurose que considera a sexualidade como um elemento natural, e não apenas como uma incidência que atinge o indivíduo desde fora. A partir desse movimento, o pensamento freudiano pode implicar o indivíduo não apenas na "escolha da neurose", mas também em sua própria causalidade. Para isso, porém, ainda é necessário percorrer alguns passos.

Em 1896, Freud escreve uma série de três artigos nos quais apresenta suas concepções acerca da etiologia das quatro estruturas clínicas que vinha trabalhando: a histeria, a neurose obsessiva, a fobia (ou histeria de angústia) e a paranoia. Trata-se dos textos "A hereditariedade e a etiologia das neuroses" (Freud, 1896b) - segundo artigo escrito originalmente em francês -, "Observações adicionais sobre as neuroses de defesa" (Freud, 1896a) e "A etiologia da histeria" (Freud, 1896c).

No primeiro deles, "A hereditariedade e a etiologia das neuroses", Freud repete as ideias que apresentou no texto do ano anterior sobre as neuroses de angústia e esboça o que desenvolve, de forma mais apurada, no segundo artigo sobre as neuroses de defesa. Ambos os artigos foram encaminhados para publicação no mesmo dia. De qualquer forma, vemos que Freud marca seu posicionamento relativo às causas das neuroses. Assim ele começa seu artigo: "Dirijo-me em particular aos discípulos de J.-M. Charcot, para formular objeções à teoria etiológica das neuroses que nos foi legada por nosso mestre" (Freud, 1896b, p. 143). Após a publicação dos "Estudos sobre histeria", não parece mais fazer sentido Freud entrar na disputa sobre esse assunto. Ele vem, então, para reiterar que não pode mais pensar na hereditariedade como o fator que rege a escolha do distúrbio psíquico.

Sua hipótese sobre o fator quantitativo do sistema psíquico já estava encaminhada e o traço da sexualidade já lhe parecia irrefutável. A pergunta sobre as causas especificas das neuroses vem então reconfirmar o que já não poderia mais ser desconfiado: todas as neuroses, seja o grupo das psiconeuroses ou das neuroses atuais, "têm como fonte comum a vida sexual do sujeito, quer residam num distúrbio de sua vida sexual contemporânea, quer em fatos importantes de sua vida passada" (Freud, 1896b, p. 148).

Se a sexualidade começa a ser concebida como um elemento natural no funcionamento das neuroses, a produção da sintomatologia ainda não é considerada como fruto deste processo. Ainda se faz necessário um fator externo que incida sobre a psique de forma a produzir uma alteração em seu funcionamento. É preciso que um evento se apresente como agente provocador. E no caso da histeria, afirma Freud,

(...) o evento do qual o sujeito reteve uma lembrança inconsciente é uma experiência precoce de relações sexuais com excitação real dos órgãos genitais, resultante de abuso sexual cometido por outra pessoa; e o período da vida em que ocorre esse 
evento fatal é a infância - até a idade de 8 a 10 anos, antes que a criança tenha atingido a maturidade sexual. (Freud, 1896b, p. 151)

A etiologia da histeria, então, se organiza em uma experiência real de ordem sexual que o sujeito sofre passivamente no período anterior à puberdade. A clínica de Freud constata que estes pacientes histéricos passaram por um "ataque brutal praticado por um adulto" ou por crianças com diferença de idade. Uma menina era submetida a relações sexuais com um menino um pouco mais velho, normalmente seu irmão, que por sua vez também havia anteriormente sofrido sedução "por uma criada ou governanta". A data em que ocorriam esses acontecimentos sexuais poderia variar, mas normalmente eram associados ao quarto ou quinto ano de idade.

Freud marca aqui a temporalidade da formação dos sintomas. A criança que foi submetida a uma excitação sexual precoce, justamente por ter ocorrido em sua primeira infância, não vai apresentar nenhuma sintomatologia. Fica evidente que Freud ainda não concebia a ideia de sexualidade infantil. Apenas mais tarde, durante a puberdade, quando os órgãos sexuais estão amadurecidos, ela poderá, a posteriori, representar o acontecimento passado como tendo sido de ordem sexual. Assim, "esse traço psíquico inconsciente é de algum modo despertado" (Freud, 1896b, p. 151), a lembrança toma um poder que não teve na época de sua formação e atua como se ela fosse um evento contemporâneo.

Essa importante proposição sobre a temporalidade na formação da neurose histérica - pela qual uma lembrança traumática sexual é despertada após a puberdade, ganhando muito mais força do que tinha em sua origem - somente pode resultar da teoria que fez Freud afastar-se de todos seus mestres, isto é, a ideia de que todas as neuroses são causadas por uma defesa. Nessa linha, Freud afirma que a neurose obsessiva percorre o mesmo processo que a histeria. Também nela se encontram lembranças de eventos sexuais precoces, que são despertadas após a puberdade. Porém, uma diferença entre a neurose obsessiva e a histeria se mostra fundamental: enquanto para a formação da histeria o sujeito sofreu passivamente uma sedução sexual, na neurose obsessiva o sujeito agiu ativamente contra um outro, e dessa ação obteve seu estímulo sexual.

Assim, afirma Freud, a neurose obsessiva é produzida por um comportamento sexual ativo que proporcionou prazer, "um ato de agressão inspirado no desejo (no caso do menino) ou de um ato de participação nas relações sexuais acompanhado de gozo (no caso das meninas)" (Freud, 1896b, p. 154). Já se estabelece também, a partir dessas constatações, a correspondência entre os pares atividade/passividade e masculino/feminino, além da hipótese de que a posição ativa dos meninos é precedida por uma posição passiva.

No texto "Observações adicionais sobre as neuropsicoses de defesa" (Freud, 1896a), enviado à publicação, conforme lemos na carta à Fliess do dia 06 de fevereiro de 1896 , no mesmo dia que o artigo anterior e o seguinte, "A etiologia da histeria" - Freud retoma os argumentos que havia apresentado dois anos antes, em seu primeiro artigo sobre as neuropsicoses de defesa, também dividindo-o em três sessões correspondentes às estruturas clínicas da histeria, da neurose obsessiva 
e da paranoia. Embora a teoria da defesa e do recalcamento sejam reapresentadas ao longo do artigo, o que se coloca como questão essencial, para Freud, é investigar como a lembrança de um acontecimento pode ser mais forte do que o evento original.

Já estava bem sustentada, para Freud, que a formação das neuroses se dá através da ação inconsciente de defesa contra uma experiência sexual passiva, no caso da histeria, e uma experiência sexual ativa, no caso da neurose obsessiva. O que agora se apresenta como problemático é compreender que, a partir dos relatos de seus pacientes, se manifesta uma diferença entre as épocas em que ocorreram os eventos traumáticos e em que os sintomas foram despertados. Se a defesa é prerrogativa de toda psiconeurose, o que se constata é que o recalcamento atua somente nas lembranças dos acontecimentos e não propriamente no momento de suas ocorrências.

Para a histeria, os "traumas sexuais devem ter ocorrido na tenra infância, antes da puberdade, e seu conteúdo deve consistir numa irritação real dos órgãos genitais (por processos semelhantes à copulação)" (Freud, 1896a, p. 164). Dos treze casos analisados por Freud, entre os responsáveis pela sedução encontravam-se as babás, as governantas e as empregadas domésticas, assim como os professores e os irmãos mais velhos. A idade que os pacientes lembravam que haviam sofrido abuso varia entre os 8 e 10 anos até os 2 anos de idade. 0 essencial da nova descoberta de Freud é que as experiências não atuam em si mesmas de forma traumática, mas sim suas revivescências, como lembranças, após a maturidade sexual.

No "Rascunho Castração" ("Um conto de fadas natalino"), enviado à Fliess no dia $1^{\circ}$ de janeiro de 1896, Freud esboça um resumo do conteúdo do que veio a ser este segundo artigo sobre as neuropsicoses, e afirma que a tendência à defesa - normal para o funcionamento contra qualquer aumento da energia psíquica - somente opera nas lembranças e nos pensamentos, e não nas percepções traumáticas. Mas a defesa torna-se prejudicial apenas quando ela atua em lembranças cujos conteúdos são capazes de produzir um aumento da quantidade de excitação do sistema psíquico. E, para Freud, as ideias sexuais são "a única possibilidade reconhecida de que uma lembrança tenha um poder liberador maior do que o que foi produzido pela experiência a ela correspondente" (Freud, 1896d, p. 164).

Em uma nota de rodapé do texto "Observações adicionais sobre as neuropsicoses de defesa" (1896a), Freud declara que somente uma teoria psicológica do recalcamento é capaz de esclarecer o motivo pelo qual apenas representações sexuais podem ser recalcados. Deve-se, para tanto, considerar alguns pressupostos, a saber, que as representações sexuais são as únicas que produzem excitações semelhantes à própria experiência; que essa excitação sexual somática produz efeitos na esfera psíquica; e que sua lembrança produz um aumento da quantidade de energia maior do que na época em que ocorreu, apenas se o evento ocorrer antes da puberdade.

Assim como a histeria, também a neurose obsessiva e a paranoia estão submetidas a essa "relação invertida entre a experiência real e a lembrança". A neurose obsessiva não se deve à posição de passividade no evento traumático, como ocorre na histeria, mas aos "atos de agressão praticados com prazer e de participação prazerosa em atos sexuais" (Freud, 1896a, p. 168), ou seja, à posição 
sexual ativa. Porém, identifica-se nas neuroses obsessivas um substrato histérico anterior à ação prazerosa, quer dizer, uma criança, antes de agir agressivamente contra outra, passou ela mesma por uma situação passiva de sedução sexual. Em função dessa dupla posição, o recalcamento que vai agir sobre 0 ato sexual prazeroso ocorrido na primeira infância vai associá-lo a ideias de autoacusação, enquanto as experiências sexuais passivas prévias são substituídas por sintomas primários, como a vergonha e a autodesconfiança.

A paranoia, por sua vez, também é enquadrada como uma neuropsicose de defesa, na medida em que se origina do recalcamento de lembranças sexuais. Seu método, porém, se difere das outras duas neuroses. Enquanto a histeria se caracteriza pela conversão somática da excitação que é produzida pelo retorno da lembrança recalcada, e a neurose obsessiva pela substituição da representação desta lembrança por outra, deslocando-a para um outro conjunto de associações, a paranoia utiliza-se da projeção da ideia recalcada sob a forma de desconfiança dirigida a outras pessoas.

Após a apresentação dos mecanismos próprios de cada estrutura, coloca-se a Freud um novo problema, a saber, o de mergulhar nos enigmas psicológicos para investigar a origem do prazer e do desprazer liberados pela excitação sexual prematura. Pelo ano de 1896, Freud ainda não esboçara a hipótese da sexualidade infantil como determinante na formação das neuroses. Sua teoria do recalcamento tende a ser justificada pela ação moralizante de forças recalcadoras de origem externa, tal como afirma no "Rascunho K":

Quando não existe vergonha (como numa pessoa do sexo masculino), ou não surge a moralidade (como nas classes mais baixas da sociedade), ou quando a repulsa é embrutecida pelas condições de vida (como nas zonas rurais), também nesses casos nenhum recalcamento e, portanto, nenhuma neurose resulta da estimulação sexual na primeira infância. (Freud, 1896d, p. 164)

Não se trata exatamente de uma hipótese na qual Freud adere firmemente, sem antes fazer um exame mais aprofundado. Para ele, não pode ser plausível pensar que o desprazer sobre a sexualidade seja produzido unicamente por fatores alheios ao indivíduo. Apenas uma teoria psicológica deve ser capaz de identificar a fonte de produção de desprazer, que é própria da sexualidade, que ativa a sensação de repugnância e reforça a moralidade. Nesse sentido, a neurose de angústia, como vimos há pouco, serve como modelo provisório para compreender que uma quantidade de excitação da vida sexual produz efeitos na esfera psíquica. Mas, "enquanto não houver uma teoria correta sobre o processo sexual, a questão de origem do desprazer que atua no recalcamento permanecerá sem resposta" (Freud, 1896d, p. 164).

Essa teoria psicologia já havia sido esboçada nas correspondências com seu amigo Wilhelm Fliess, especialmente com a escrita do trabalho - engavetado por mais de meio século até sua publicação - que veio a ser conhecido como "Projeto para uma psicologia científica" (Freud, 
1950[1895]). Os textos publicados por volta desse período, porém, se constroem sob efeito da tentativa de elaboração de uma teoria psicológica. Em 1896 Freud publica uma conferência que havia dado à Sociedade de Psiquiatria de Viena, cujo título é "A etiologia da histeria" (Freud, 1896c). Na carta que envia a Fliess no dia 26 de abril de 1896, ele relata que essa palestra teve uma "receptividade gélida por parte daqueles imbecis" e que o eminente psiquiatra Richard von KrafftEbing (1840-1902), que presidia a sessão e cuja obra Psychopathia Sexualis veio a cunhar as categorias de sadismo e masoquismo, respondeu que parecia um "conto de fadas infantil".

O assunto tão criticado da palestra de Freud era, para ele, a solução de um problema de mais de mil anos, a saber, a consideração da importância das experiências sexuais infantis na formação dos sintomas neuróticos. Assim como vimos nos trabalhos anteriores, essas experiências ainda eram efeito das ações dos adultos sobre as crianças. Entretanto, se "A etiologia da histeria" se sustenta sobre uma ideia que vai ser derrubada em menos de um ano - isto é, a teoria da sedução infantil - ela dá abertura, ao mesmo tempo, para uma das teses centrais dos "Três ensaios sobre a teoria da sexualidade" (Freud, 1905), qual seja, o caráter perverso polimorfo da sexualidade infantil.

Se o comentário de Kraff-Ebing - de que os pressupostos sobre a etiologia da histeria seriam como contos de fadas infantis - repercutiu negativamente em Freud, ele anuncia um ponto de verdade que não se coloca totalmente dissociado do método que a psicanálise propõe. Ora, um dos méritos de Freud e Breuer é terem considerado que as falas das histéricas não poderiam ser tomadas como verdades em si mesmas, na medida em que elas ocultam aquilo que é mais importante a elas. Foi necessário, então, adotar uma metodologia que situe aquele que escuta em um certo distanciamento do paciente, de modo que consiga suspender a significação de seu discurso. Daí, portanto, a aproximação da psicanálise com os contos de fadas, quando ambos transpõem o valor de verdade de um discurso para o de uma construção ficcional.

Essa metodologia, aponta Freud, deve ser como a do arqueólogo ou explorador que, diante de uma região desconhecida, torna-se curioso sobre as histórias das ruínas, dos restos de paredes, dos fragmentos de colunas e lápides apagadas, mas que não se contenta em saber a partir do que está visível, em conversar com os moradores. Investigar aquilo que se encontra para além do seu alcance de visão - através de picaretas, pás e enxadas - pode levá-lo a descobrir que essas ruínas eram parte de uma muralha, de um palácio ou de um templo; que as inscrições das lápides são de uma linguagem que, quando decifrada, revelam informações sobre o passado mais remoto dessa região.

A recomendação de Freud para que se fale a respeito dos sintomas, esses símbolos mnêmicos de experiências mais antigas, serve para encontrar o caminho de volta à lembrança traumática, a ponto de chegar a uma série de experiências cujas lembranças remontam eventos sexuais que não se limitam mais à puberdade, mas que remetem ao período da primeira infância. Mas, pergunta Freud: "será que não temos o direito de presumir que nem mesmo a infância é desprovida de leves excitações sexuais, e que o futuro desenvolvimento sexual talvez seja decisivamente influenciado pelas experiências infantis?" (Freud, 1896c, p. 199). Se assim fosse, as 
experiências sexuais infantis passariam a influenciar a hipótese de que os efeitos psíquicos são produzidos apenas por traços mnêmicos.

Mas Freud ainda acreditava que as atividades sexuais eram decorrentes de abusos externos à criança ("uma babá, uma governanta, um tutor ou, infelizmente, com frequência grande demais, um parente próximo"), na medida em que elas não saberiam realizar atos sexuais, "a menos que tenham sido previamente seduzidas". Por isso, para ele, a base da neurose sempre teria origem na infância pela ação de um outro. A universalidade das experiências sexuais infantis ainda era uma hipótese impossível de ser considerada, pois, para sustentar sua teoria, bastava a comprovação da ocorrência em todos os casos de histeria. Entretanto, parece que no desenrolar desse artigo, Freud vai fragilizando pouco a pouco sua certeza sobre a necessária passividade do neurótico diante de um acontecimento sexual para pressupor que também ele é um participante ativo desse ato. Nesse sentido, parece que Freud vai tateando a hipótese de que também há na sexualidade infantil um infantil da sexualidade. Assim, afirma que "é necessário um certo estado infantil das funções psíquicas, assim como do sistema sexual, para que uma experiência sexual ocorrida durante esse período produza, mais tarde, sob a forma de lembrança, um efeito patogênico" (Freud, 1896c, p. 208). Porém, logo a seguir ele recusa a desenvolver qualquer outra afirmação a respeito desse "infantilismo psíquico".

$\mathrm{Na}$ terceira parte deste artigo "A etiologia da histeria", Freud (1896c) mostra sua instabilidade quanto à hipótese de um infantil da sexualidade. Se ele propõe retirar o peso da cena sexual infantil como causa da histeria - na medida em que "todos os casos de histeria apresentam sintomas determinados não por experiências infantis, mas por experiências posteriores" -, logo mais adiante ele afirma que alguns sintomas podem ser remetidos "às primeiríssimas experiências", desde que se tratem de sintomas relativos ao conteúdo sensorial das cenas infantis, isto é, a sensações e excitações dos órgãos genitais ou outras partes do corpo.

Freud parece aqui expandir a noção de sexualidade para as excitações de outras zonas corporais, ideia que vem a ser desenvolvida na caracterização da sexualidade das crianças como perverso-polimorfa. Os sintomas histéricos mostram que as cenas sexuais infantis incluem abusos também em zonas como o ânus e a boca, de modo a aparecerem sob a forma de distúrbios alimentares. De qualquer forma, entre a valorização da cena posterior, ocorrida durante a puberdade, e a cena primária, ocorrida na infância, há um determinante comum que faz com que elas concordem entre si. E assim Freud projeta que o exame mais minucioso dos eventos do campo psíquico que permanecem inconscientes "repousa uma vez mais no campo da psicologia - e, o que é mais importante, de uma psicologia de um tipo para o qual os filósofos pouco fizeram para nos preparar" (Freud, 1896c, p. 213). 


\section{Referências bibliográficas}

Freud, S. \& Breuer, J. (1990). Estudos sobre histeria. Edição standard brasileira das obras psicológicas completas de Sigmund Freud (Vol. 2, pp. 39-319). Rio de Janeiro: Imago. (Trabalho original publicado em 1893-1895).

Freud, S. (1990). Histeria. Edição standard brasileira das obras psicológicas completas de Sigmund Freud (Vol. 1, pp. 77-95). Rio de Janeiro: Imago (Trabalho original publicado em 1888).

Freud, S. (1990). As neuropsicoses de defesa. Edição standard brasileira das obras psicológicas completas de Sigmund Freud (Vol. 3, pp. 53-66). Rio de Janeiro: Imago (Trabalho original publicado em 1894a).

Freud, S. (1990). Obsessões e fobias: seu mecanismo psíquico e sua etiologia. Edição standard brasileira das obras psicológicas completas de Sigmund Freud (Vol. 1, pp. 79-86). Rio de Janeiro: Imago (Trabalho original publicado em 1894b).

Freud, S. (1986). Rascunho E: Como se origina a Angústia. In Masson, J. M. (Ed.). A Correspondência Completa de Sigmund Freud para Wilhelm Fliess - 1887-1904 (pp. 78-83). Rio de Janeiro: Imago (Trabalho original publicado em 1894c).

Freud, S. (1990). Sobre os fundamentos para destacar da neurastenia uma síndrome específica denominada "neurose de angústia". Edição standard brasileira das obras psicológicas completas de Sigmund Freud (Vol. 3, pp. 93-116). Rio de Janeiro: Imago (Trabalho original publicado em 1895).

Freud, S. (1990). Observações adicionais sobre as neuropsicoses de defesa. Edição standard brasileira das obras psicológicas completas de Sigmund Freud (Vol. 1, pp. 41-52). Rio de Janeiro: Imago (Trabalho original publicado em 1896a).

Freud, S. (1990). A hereditariedade e a etiologia das neuroses. Edição standard brasileira das obras psicológicas completas de Sigmund Freud (Vol. 3, pp. 163-188). Rio de Janeiro: Imago (Trabalho original publicado em 1896b).

Freud, S. (1990). A etiologia da histeria. Edição standard brasileira das obras psicológicas completas de Sigmund Freud (Vol. 3, pp. 189-220). Rio de Janeiro: Imago (Trabalho original publicado em 1896c).

Freud, S. (1986). Carta de $1^{\circ}$ de dezembro de 1896 (Rascunho K: "Um conto de fadas natalino"). In Masson, J. M. (Ed.). A Correspondência Completa de Sigmund Freud para Wilhelm Fliess - 18871904 (pp. 163-170). Rio de Janeiro: Imago (Trabalho original publicado em 1896d).

Freud, S. (1990). A história do movimento psicanalítico. Edição standard brasileira das obras psicológicas completas de Sigmund Freud (Vol. 14, pp. 13-76). Rio de Janeiro: Imago (Trabalho original publicado em 1914).

Freud, S. (1990). Pulsões e destinos da pulsão. Edição standard brasileira das obras psicológicas completas de Sigmund Freud (Vol. 14, pp. 117-146). Rio de Janeiro: Imago (Trabalho original publicado em 1915). 
Citacão/Citation: Costa, A. O. (nov. 2013 a abr. 2014). Defesa e sexualidade nos primórdios da psicanálise. Revista aSEPHallus de Orientação Lacaniana, 9(17), 80-96. Disponível em www.isepol.com/asephallus. doi: 10.17852/1809-709x.2019v9n17p80-96.

Editor do artigo: Tania Coelho dos Santos.

Recebido/Received: 14/06/2013 / 06/14/2013.

Aceito/Accepted: 23/10/2013 / 10/23/2013.

Copyright: (c) 2013 Associação Núcleo Sephora de Pesquisa sobre o moderno e o contemporâneo. Este é um artigo de livre acesso, que permite uso irrestrito, distribuição e reprodução em qualquer meio, desde que o autor e a fonte sejam citados/This is an open-access article, which permites unrestricted use, distribution, and reproduction in any medium, provided the author and source are credited. 